\title{
Ciberbullying desde la perspectiva del estudiantado: “Lo que vivimos, vemos y hacemos"
}

\author{
Cyberbullying From Students' Perspective: “What We Live, See and Do"
}

\section{Cyberbullying a partir da perspectiva de estudantes: "o que vivemos, vemos e fazemos"}

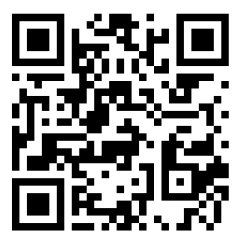

\author{
Ana Lucía Chaves-Álvarez \\ Universidad Nacional \\ Instituto de Estudios Interdisciplinarios de la Niñez y la Adolescencia \\ Heredia, Costa Rica \\ analuciachavesalvarez@gmail.com \\ https://orcid.org/0000-0002-0104-0149 \\ María Ester Morales-Ramírez \\ Universidad Nacional \\ Instituto de Estudios Interdisciplinarios de la Niñez y la Adolescencia \\ Heredia, Costa Rica \\ teymorales@gmail.com \\ iD https://orcid.org/0000-0003-1088-1895 \\ Margarita Villalobos-Cordero \\ Universidad Nacional \\ Instituto de Estudios Interdisciplinarios de la Niñez y la Adolescencia \\ Heredia, Costa Rica \\ villalobos.margarita@gmail.com \\ https://orcid.org/0000-0003-4183-3757
}

Recibido • Received • Recebido: 13 / 03 / 2018

Corregido • Revised • Revisado: 06 / 10 / 2019

Aceptado • Accepted • Aprovado: 04 / 12 / 2019 
doi: http://doi.org/10.15359/ree.24-1.3

URL: http://www.una.ac.cr/educare

CORREO: educare@una.cr

Resumen: El presente trabajo se deriva de la investigación ciberbullying: Conociendo su impacto en el desarrollo socioemocional de la población adolescente y reflexionando acerca de posibles formas de prevenirlo, código: 0236-13, en el que se tomó en cuenta la opinión de adolescentes, docentes, personal directivo y figuras parentales. El artículo se enfoca en la percepción que tienen, del ciberbullying o acoso cibernético, las personas adolescentes. Por lo tanto, tiene el objetivo de dar a conocer las opiniones del estudiantado respecto al concepto, roles, impacto y acciones tomadas por las personas adultas sobre este fenómeno social. El estudio tiene un enfoque mixto, de tipo exploratorio y descriptivo del impacto que el acoso cibernético tiene en el desarrollo socioemocional de adolescentes. Se obtuvo respuestas de 447 estudiantes de $7^{\circ}$ a $11^{\circ}$ nivel, en un rango de edad de 12 a 19 años, de 4 centros educativos de secundaria, ubicados en la provincia de Heredia y San José, Costa Rica, la selección fue intencional, después de solicitar los permisos respectivos. La información se obtuvo mediante un cuestionario con preguntas abiertas y cerradas, que se analizó desde la perspectiva cuantitativa y cualitativa, incluye categorías emergentes elaboradas a partir de las respuestas aportadas. Los resultados más notables evidencian que la mayoría hace uso de los medios cibernéticos y tecnológicos en el colegio y hogar, sin supervisión adulta. Son acosados el $23.7 \%$ de $7^{\circ}$ a $9^{\circ}$ año y $16.9 \%$ de $10^{\circ}$ y $11^{\circ}$ nivel. Los medios más empleados para el acoso son Facebook, mensajes de texto y llamadas telefónicas, lo cual incide, principalmente, en el área socioemocional, a razón del temor, inseguridad y desconfianza que experimentaron. En opinión de las investigadoras, se podría concluir que el acoso sufrido por esta población adolescente no se tipifica como ciberbullying, a razón de que la mayoría conoce la identidad de la persona acosadora: no se cumple la principal característica de esta problemática, que es el anonimato. El estudio realizado se basa en una llamada de atención para las familias, docentes y figuras parentales, con respecto al papel que deben asumir en la vida del grupo de adolescentes, el tipo de relaciones que entabla esta población y las necesidades socioemocionales que tiene.

Palabras claves: Ciberbullying; maltrato; acoso; adolescentes; familias; colegio; docentes.

Abstract: The present work is derived from the research "Cyberbullying: knowing its impact on the socio-emotional development of the adolescent population and reflecting on possible ways to prevent it," which considered the opinion of adolescents, teachers, directors, and parents. The article focuses on the perception of adolescents on cyberbullying. Therefore, its goal is to report the opinions of students about the concept, roles, impact, and actions taken by adults regarding this social phenomenon. The study has an exploratory and descriptive mixed-type approach of the impact of cyberbullying on the socio-emotional development of adolescents. Answers were obtained from 447 students from 7th to 11th grade, in an age range of 12 to 19 years old, from four secondary schools, located in the provinces of Heredia and San José, Costa Rica. The students were intentionally selected, after coordination with authorities and parents to obtain the respective endorsements. The information was collected through a questionnaire with open-ended and closed-ended questions. Later, it was analyzed from the quantitative and qualitative perspectives, including emerging categories elaborated from the answers provided. The most notable results show that the majority of students use cybernetic and technological tools in school and at home, without adult supervision. Bullying occurs in $23.7 \%$ of students in 7 th to 9 th grades, and in $16.9 \%$ of students in 10th and 11 th grades. The means of harassment most widely used are Facebook, text messages, and telephone calls; the harassment affects the socio-emotional health, due to the fear, insecurity, and distrust experienced. According to the researchers, it could be concluded that the harassment suffered by this adolescent 
population is not typified as cyberbullying, because most victims know the identity of the harasser, and the problem does not fulfil the main feature that is anonymity. The study is based on a warning for families, teachers, and caregivers regarding the role they should play in the lives of adolescents, the types of relationships they establish, and the socio-emotional needs of this population.

Keywords: Cyberbullying; abuse; harassment; adolescents; families; school; teachers.

Resumo: O presente trabalho é derivado da pesquisa "Ciberbullying: conhecer seu impacto no desenvolvimento socioemocional da população adolescente e refletir sobre possíveis formas de prevenir", que levou em consideração a opinião de adolescentes, professores, diretores e responsáveis. $\mathrm{O}$ artigo enfoca na percepção que adolescentes tem de ciberbullying, permitindo conhecer as opiniões de estudantes sobre o conceito, os papéis, o impacto e as ações tomadas por pessoas adultas. $\mathrm{O}$ estudo possui uma abordagem mista, tipo exploratório e descritivo do impacto que o ciberbullying tem no desenvolvimento socioemocional de uma pessoa adolescente. Foram obtidas respostas de 447 estudantes do $7^{\circ}$ ao $11^{\circ}$ ano, com faixa etária de 12 a 19 anos, de 4 centros educacionais secundários, localizados na província de Heredia e San José, Costa Rica, selecionados intencionalmente, após a coordenação com autoridades e responsáveis para obter a permissão. A informação foi obtida através de um questionário com perguntas abertas e fechadas e foi analisado a partir da perspectiva quantitativa e qualitativa, incluindo categorias emergentes elaboradas a partir das respostas fornecidas. Os resultados mais notáveis mostram que a maioria usa meios cibernéticos e tecnológicos na escola e em casa, sem supervisão de um adulto. Eles são assediados $23,7 \%$ do $7^{\circ}$ ao $9^{\circ}$ ano e $16,9 \%$ do $10^{\circ}$ ao $11^{\circ}$ ano. Os meios de assédio mais utilizados são o Facebook, mensagens de texto e ligações, afetando principalmente a área socioemocional, devido ao medo, insegurança e desconfiança que experimentaram. Na opinião das pesquisadoras, pode-se concluir que o assédio sofrido por essa população adolescente não é tipificado como Cyberbullying, porque a maioria conhece a identidade do assediante, não cumprindo-se, a principal característica desse problema, que é o anonimato. $O$ estudo realizado procura chamar a atenção as famílias, docentes e responsáveis, sobre o papel que devem assumir na vida dos adolescentes, o tipo de relações que eles estabelecem e as necessidades socioemocionais que possuem.

Palavras-chave: Ciberbullying; abuso; assédio; adolescentes; famílias; escola; professores.

\section{Introducción}

El fenómeno del ciberbullying se ha convertido en un tema que da de qué hablar. Leemos, escuchamos, lo vemos en redes sociales, noticiarios, programas educativos, películas o entrevistas. En el Instituto de Estudios Interdisciplinarios de la Niñez y la Adolescencia (INEINA) de la Universidad Nacional de Costa Rica (UNA), surge la inquietud de indagar sobre esta temática, partiendo de la opinión de diferentes actores y actoras del proceso educativo. Por esto desarrolla una amplia investigación titulada Ciberbullying: Conociendo su impacto en el desarrollo socioemocional de la población adolescente y reflexionando acerca de posibles formas de prevenirlo, código: 0236-13. En dicha investigación se tomó en cuenta la opinión de 
doi: http://doi.org/10.15359/ree.24-1.3

URL: http://www.una.ac.cr/educare

CORREO: educare@una.cr

adolescentes, docentes, directores, directoras y figuras parentales. No obstante, se considera fundamental hacer énfasis sobre este tema, a partir de la vivencia de estudiantes de secundaria de diversos colegios del país. ¿Qué es el ciberbullying?, ¿qué opina el estudiantado de secundaria sobre esto?, ¿cómo lo viven estos y estas jóvenes?, ¿qué consecuencias tiene?, ¿cuál es el apoyo que ellos y ellas reciben? El presente artículo expone las respuestas a estas interrogantes.

\section{Antecedentes de la temática}

Sin duda alguna, la revolución tecnológica que vivimos actualmente ha traído cambios en las formas de vida y convivencia de las personas. Al respecto, Castro y Reta (2013) plantean lo siguiente:

Los medios de comunicación contribuyen para que las personas estén más integradas en el mundo y sientan que pertenecen a una comunidad donde se borran las fronteras. El sentimiento de identidad no se explica ya exclusivamente por la nacionalidad, sino también por la pertenencia a "tribus" en línea y redes sociales virtuales, quienes en permanente conexión y a través de una superficial comunicación, convocan individuos transnacionalizados culturalmente. (Castro y Reta, 2013, p. 86)

No obstante, es importante saber que esta nueva forma de comunicación con el mundo puede "conducir a una peligrosa despersonalización o a una subjetividad compartida" (Castro y Reta, 2013, p. 86). Tal es el caso del inevitable acceso de las personas menores de edad, sin el consentimiento o tutela de las figuras parentales, lo que las expone a la manipulación de personas adultas mal intencionadas.

Castro y Reta (2013) agregan que, a partir del 2011, las personas jóvenes han mostrado un significativo cambio en el uso de la televisión, la computadora y los dispositivos de telefonía móvil, con una tendencia a preferir el celular o el internet como medios para buscar información.

De igual manera; los autores señalados explican:

Gracias a la tecnología contaremos con información y nos comunicaremos al instante, pero la manera en que utilicemos estos recursos, la forma en que filtremos la inmensa cantidad de datos para encontrar lo que necesitamos y la forma en que nos cibercomportemos depende de nosotros. Para eso habrá que formar en nuevas competencias, no sólo tecnológicas sino también pertinentes a las formas necesarias de interacción para la ciudadanía digital o el comportamiento cívico en la Red. (Castro y Reta, 2013, p. 89)

Castro y Reta (2013) aluden a los resultados derivados de investigaciones que en materia de ciberbullying se han llevado a cabo, a saber: 
- Las mujeres tienden a ser más víctimas de ciberbullying que los varones.

- Las personas con discapacidad son más propensas a ser víctimas de ciberbullying.

- Algunos sujetos docentes tienen antecedentes de ciberbullying.

- En la mayoría de los casos la agresión se inició como bullying y continuó mediante el acceso a la red.

- Las principales agresiones fueron con mensajes de texto, email, envío de comentarios desagradables por medio de su perfil y las llamadas al celular con la intención de herir los sentimientos, reírse o atemorizar a la víctima,

- El ciberbullying, según denuncia de la ONG británica Beatbullying, está llevándose a cabo mediante la plataforma de los juegos online, situación que detectó mediante el estudio acerca de la violencia virtual. Además existe incapacidad por parte de las páginas web de juegos y otros servicios para verificar la edad del público usuario, de manera que se prevenga el acceso de personas menores a juegos inapropiados.

- En España, a través de una encuesta, se detectó que el $18 \%$ de 2000 personas entre 11 y 17 años, en algún momento de su vida, había enviado algún mensaje intimidatorio utilizando su celular.

- Castro (citado por Castro y Reta, 2013) apunta que el Observatorio de la Convivencia Escolar de la Universidad Católica Argentina reveló que alrededor del $20 \%$ del estudiantado consultado manifestó haber sufrido violencia a través de los celulares o PC, de estos el $4.6 \%$ sufrió ciberacoso y el $11 \%$ aceptó acosar a otra persona.

Castro (2013) también destaca otros resultados relacionados con estudios sobre ciberbullying:

- Las tendencias en alza son: el robo de la contraseña, la usurpación de la identidad online y la publicación de fotos sin permiso y con la clara intención de humillar.

- Los ataques menos frecuentes son aquellos que se realizan a través de la creación de páginas web denigrantes o grupos en una red social y mediante un vídeo online (Castro, 2013, p. 63).

\section{Uso de tecnología y redes en Costa Rica}

Se considera importante hacer referencia a la utilización de las redes sociales en Costa Rica, como una forma de contextualizar lo que está ocurriendo sobre esta temática. En este sentido, Pérez (2014) con la colaboración de PANIAMOR, realizaron una investigación que permitió conocer la frecuencia con la que las personas de 10 a 13 años utilizan el teléfono celular en el área metropolitana. 
doi: http://doi.org/10.15359/ree.24-1.3

URL: http://www.una.ac.cr/educare

CORREO: educare@una.cr

En esta investigación se encontraron los siguientes datos, sin diferencia significativa entre género o centro educativo público y privado:

En el ámbito nacional se sabe que un $84 \%$ de los niños y niñas de 10 a 12 años consultados ... posee teléfono celular (Pérez, 2014). De ellos, el 67\% tiene conexión a Internet en sus celulares. No se cuenta con información específicamente sobre los llamados teléfonos inteligentes o tabletas, pero se podría suponer que igualmente su tenencia es creciente. Por supuesto, estas tecnologías siguen evidenciando la brecha digital, y aunque una extensa cantidad de la población posee teléfono celular, solo un número más reducido posee Internet u otro tipo de TM. (Pérez, 2014, p. 11)

De acuerdo con los datos anteriores, es evidente cómo el uso del teléfono celular es parte de la cotidianeidad de las personas menores de edad. A esto, Pérez (2014) añade que según las opiniones de las educadoras de niños y niñas de 10 a 12 años, sobre la forma de utilizar el teléfono celular, se destacan varios usos:

1. Entretenimiento: se refiere al uso de juegos, escuchar música, ver Youtube, usar la internet o enviar mensajes de texto....

2. Usos escolares: incluye tomar apuntes, usar la agenda, usar aplicaciones de utilidad para las tareas escolares, usar el reloj y el despertador, el correo electrónico y el uso de aplicaciones científicas. ...

3. Comunicación: En este factor se incluye el uso de Facebook, Twitter, Instagram, Skype o Facetime, Whatssap, Snapchat, tomar fotografías y el uso de Spotify. ... (Pérez, 2014, p. 29)

Siguiendo con Pérez (2014), cabe anotar que surge como otro resultado relevante que el 56.41 $\%$ de los niños y niñas participantes tenía tableta. Las personas docentes de esta población infantil opinan que los niños y niñas utilizan la tableta en actividades relacionadas con el entretenimiento (Internet, YouTube, videojuegos, música y fotos); las redes secundarias (Sype, Twitter, Spotify, Instragram) y el uso escolar (lectura de libro, utilizar la agenda y hacer anotaciones).

Desde la perspectiva de las y los docentes, las figuras parentales emplean un tipo de mediación predominantemente permisiva ..., seguido por la mediación de acompañamiento ... y la prohibitiva ... Esto significa que, las personas docentes, madres y padres no controla el tipo de uso del teléfono celular o la Tablet que hacen sus hijas e hijos, en menor medida los guían y orienten en su uso o lo restringen y limitan. (Pérez, 2014, p. 38)

Otros datos relevantes reportados por Pérez (2014) y que tienen que ver con el uso de las redes sociales por parte de las personas jóvenes son: 
- Las familias (padres y madres de personas menores de 10 a 12 años), no consideran riesgoso que realicen actividades como conversar por teléfono, enviar mensajes de texto a individuos desconocidos o aceptar invitaciones en redes sociales de personas que no conocen).

- Los niños y niñas participantes no reconocen como riesgosas conductas o actividades que tienen esta característica. A su vez, opinan que las conductas riesgosas tienen que ver con un tipo de mediación permisiva por parte de las familias.

- "Tanto la presencia de matonismo como de victimización parece estar vinculado con la satisfacción de la necesidad de autonomía mediante el uso de estas tecnologías" (Pérez, 2014, p. 72).

- "Aunque parece ser que la mayoría de niñas y niños no ha sido víctima de cibermatonismo ... si se pueden identificar casos que han sido tanto víctimas como perpetradores, por lo que las acciones para su prevención deben de continuarse" (Pérez, 2014, pp. 78-79).

- "La necesidad de afirmar la propia identidad o las propias capacidades o habilidades se asocia con la presencia de conductas de riesgo y con el ciber-matonismo" (Pérez, 2014, p. 79).

De estos resultados se desprende el papel de la familia ante este fenómeno social, así como la falta de considerar riesgoso el uso de estos medios tecnológicos tanto por el estudiantado, como por las figuras parentales. Sin duda alguna, esto tiene consecuencias en la forma en la que las personas menores de edad se interrelacionan mediante la tecnología.

\section{Normativa nacional vigente relacionada con el ciberbullying}

Este marco legislativo se considera relevante, debido a que es el que establece normativas que permiten prevenir y abordar esta situación.

En octubre del 2015, el Ministerio de Educación Pública puso en vigencia el "Protocolo de actuación para las situaciones de Bullying". Si bien este documento rige para situaciones de ciberbullying que pueda presentarse en los centros educativos, solo menciona esta problemática cuando se resalta que la violencia que se presente podría ser"de tipo verbal, físico, psicológica, de índole sexual, material o cibernética" (Ministerio de Educación Pública [MEP], 2015, p. 4) y cuando se apunta que uno de los tipos de bullying es el ciberbullying entendido como:

Usar las Tecnologías de la Información y la Comunicación (TIC) para hacer bullying: mensajes de texto, redes sociales, por Internet, teléfono móvil, por fotos, videos, chats, por ejemplo. Basta con subir una sola vez una imagen a una red social y la repetición se reproduciría cada vez que alguien la vea, la comparta y existan nuevos comentarios 
doi: http://doi.org/10.15359/ree.24-1.3

URL: http://www.una.ac.cr/educare

CORREO: educare@una.cr

abusivos que acompañen a la imagen. Ayudar a que una agresión se propague por la red causa daño y hace responsable a esa persona también, porque no puede haber iniciado ni instado la agresión, pero la perpetra al continuarla o repetirla, al mantener viva la agresión que afecta a la persona violentada. (MEP, 2015, p. 7)

Posterior al protocolo citado anteriormente, la Asamblea Legislativa de la República de Costa Rica aprobó, el 27 de junio del 2016, la creación de la "Ley para la prevención y establecimiento de medidas correctivas y formativas frente al acoso escolar o bullying". Con esto, queda en evidencia que en Costa Rica se considera una necesidad regular lo relacionado con este fenómeno, en los ambientes y contextos educativos.

Esta ley tiene como objetivo:

La prevención y el establecimiento de medidas correctivas y formativas ante conductas de acoso escolar o bullying, con el fin de lograr que los niños, las niñas, los adolescentes y las personas jóvenes matriculadas en un centro educativo, sea público o privado, en todas las modalidades educativas previstas dentro del Sistema Educativo Costarricense, puedan exigir que protejan su integridad física, moral y psicológica de cualquier acción u omisión que vulnere derechos en el ámbito de la convivencia estudiantil, de conformidad con el Código de la Niñez y la Adolescencia y demás normativa que resguarde los derechos de la niñez, adolescencia y juventud. (Asamblea Legislativa de la República de Costa Rica, 2016, p. 2)

Adicionalmente, la ley precitada hace referencia al ciberbullying, especialmente cuando se recurre al empleo de las tecnologías de la información y la comunicación para realizar actos de acoso escolar, de ahí que en su Artículo 2, concerniente al interés público, cita que siendo la ley de orden público y de interés social "está destinada a lograr un ambiente libre de acoso escolar o bullying físico, sexual, psicológico, verbal o cibernético, procurando el respeto de los derechos humanos y el cumplimiento de los principios de tolerancia, respeto a la dignidad humana, igualdad, equidad y convivencia pacífica y social" (Asamblea Legislativa de la República de Costa Rica, 2016, pp. 1-2).

Más específicamente, acerca del tema del acoso cibernético, el documento plantea los puntos que seguidamente se detallan:

- ARTíCULO 3.- inciso b) define el Ciberbullying como"la utilización de las Tecnologías de la Información y la Comunicación (TIC) para hacer acoso escolar o bullying (Internet, redes sociales virtuales, telefonía móvil, video juegos "online", "YouTube" o cualquier otro medio virtual que surja en el futuro)" (Asamblea Legislativa de la República de Costa Rica, 2016, p. 1).

-Respecto al ámbito de aplicación de la ley, el Artículo 5.-inciso c es claro en señalar que también es de aplicación obligatoria en "todos los hechos de acoso escolar o bullying que se puedan dar en el ciberespacio, en las Tecnologías de la Información y la Comunicación, entre estudiantes" (Asamblea Legislativa de la República de Costa Rica, 2016, p. 3).

Ana Lucía Chaves-Álvarez, María Ester Morales-Ramírez y Margarita Villalobos-Cordero

Los artículos de la Revista Electrónica Educare del Centro de Investigación y Docencia en Educación de la Universidad Nacional, Costa Rica, se comparten bajo términos de la Licencia Creative Commons: Reconocimiento, No Comercial, Sin 0bra Derivada 3.0 Costa Rica. Las autorizaciones adicionales a las aquí delimitadas se pueden obtener en el correo: educare@una.cr 
-EI ARTíCULO 6.- en su inciso e) plantea como uno de los tipos de acoso escolar el Ciberbullying o acoso cibernético el cual "se realiza mediante el uso de cualquier medio electrónico como Internet, páginas web, redes sociales, blogs, correos electrónicos, mensajes, imágenes o vídeos por teléfono celular, computadoras, videograbaciones u otras tecnologías digitales, de información y comunicación" (Asamblea Legislativa de la República de Costa Rica, 2016, p. 4).

\section{Definiendo el término ciberbullying}

La violencia escolar concebida como el comportamiento u omisión que con clara intención de hacer daño se practica entre los diferentes actores de la comunidad educativa, esto es, estudiantes, personal docente, personal administrativo y figuras parentales, ha ido evolucionando, no solo en cifras sino además en las formas en las que se manifiestan y las herramientas empleadas para llevarlas a cabo. Esta manifestación de la violencia puede darse en diversos contextos, ya sea en las instalaciones propias de los centros educativos o bien en otros que directa o indirectamente están relacionados con la escuela y el hogar (alrededores de la escuela o lugares donde se desarrollan actividades extraescolares) (Ferro, 2014).

Castro y Reta (2013) añaden que las formas mediante las cuales la violencia se expresa están determinadas por todos los elementos que la cultura pone a disposición, de ahí que sean hoy en día las nuevas tecnologías y pantallas, las empleadas para hacer daño.

Aunado a lo antes citado, el uso de la internet por parte de la población adulta ha alcanzado niveles impensados y en este proceso de digitalización, las personas menores de edad -especialmente la población adolescente-, no han sido la excepción. Esta es una de las herramientas que con mayor intensidad ha invadido nuestra cotidianidad con una amplia gama de propósitos, algunos de los cuales, no tan positivos, conllevan a la aparición de dificultades entre el público usuario asiduo a este mecanismo de comunicación.

Tal es el caso del ciberbullying considerado un tipo de bullying, cuya principal diferencia con este último es el empleo de las TIC para llevar a cabo el acoso entre personas menores de edad o bien como lo visualizan Kowalski, Limber y Agatston (2010) "un nuevo tipo de acoso que se conoce con el nombre de acoso cibernético, crueldad social on line o acoso electrónico" (p. 80), coincidente con Buelga, Cava y Musitu (2010) que destacan que las nuevas TIC han promovido sin intención, una "nueva forma de intimidación y de acoso entre los adolescentes conocida como ciberbullying" (p. 784).

Al respecto, las referencias consultadas dan cuenta de que el término es tan complejo que son diversas las características a tomar en consideración para poder determinar, si el conflicto que se presenta corresponde o no a una situación de ciberbullying, especialmente, porque podrían presentarse episodios de hostigamiento usando las TIC que no se da entre iguales, tal 
doi: http://doi.org/10.15359/ree.24-1.3

URL: http://www.una.ac.cr/educare

CORREO: educare@una.cr

es el caso de uno o varios estudiantes ridiculizando a una docente $y$, adicionalmente, porque los métodos empleados para acosar electrónicamente a una persona pueden ser muy diversos y la persona acosadora se puede identificar.

Kowalski et al. (2010) refuerzan el punto precitado, ya que, en su opinión, la experiencia podría ser tan ambigua que se dificulta la identificación del episodio y, más aún, si el criterio para delimitarlo es la edad de los sujetos involucrados en el acoso. Fundamentan el comentario en el hecho de que para Aftab (citada por Kowalski et al., 2010), para que una página de internet sea considerada como medio para el acoso cibernético, debe darse entre menores de edad y agrega que cuando "un adulto aparece implicado, la conducta se califica de hostigamiento cibernético o ciberpersecusión" (p. 82) y que este comportamiento obsesivo por parte de una persona adulta, "JAMÁS recibe el nombre de ciberacoso" (p. 82).

Otra proposición es la de Luengo (2014), para quien el ciberbullying "es un tipo concreto de acoso en la red aplicado en un contexto en el que únicamente están implicados menores" (p. 28).

Si bien Ferro (2014) manifiesta que no toda conducta irregular e indeseable mediante las $\mathrm{TIC}$, el hecho de que esté relacionada con las relaciones entre pares debe ser considerado como ciberacoso, esta problemática sí implica "acosar en el contexto digital o aprovecharse de él para hacerlo diferente, expansivo y muy frecuentemente más virulento" (p. 79).

Son diversas las definiciones que acerca del ciberbullying se derivaron de la revisión bibliográfica. Si bien presentan elementos en común, también tienen su propia especificidad, tal es el caso de Manson (citado por del Río, Sádaba y Bringué, 2010), quien exterioriza que el ciberbullying es el uso deliberado que hace una persona o un grupo de las TIC "de manera repetida para el acoso o amenaza hacia otro individuo o grupo mediante el envío o publicación de texto cruel y/o gráficas a través de los medios tecnológicos" (p. 117).

Por su parte, del Rey et al. (2011) conciben el ciberbullying como "el hostigamiento reiterado que unos escolares pueden ejercer sobre otro u otros por medio de las Tecnologías de la Información y la Comunicación -las TIC-y en el que las víctimas sufren consecuencias que merman su calidad de vida" (p. 10).

Molina y Vecina (2015) lo conceptualizan como un abuso psicológico entre personas de edad similar, pero a diferencia del bullying, este acoso es anónimo y se realiza empleando las nuevas tecnologías de información y comunicación. Aclaran que es importante tener en cuenta que en el ciberbullying quien acosa es una persona menor de edad, en tanto que en el ciberacoso "el atacante tiene que ser una persona adulta" (Molina y Vecina, 2015, p. 48).

De todas estas conceptualizaciones sobre el ciberbullying, se desprenden las características de este fenómeno. Una de las características más relevantes tiene que ver con la facilidad que otorgan los medios tecnológicos para poder acosar a una persona. 


\section{Características del ciberbullying}

Según Molina y Vecina (2015), es una "forma deliberada e intencionada para dañar a la persona acosada, siendo persistente en el tiempo" (p. 48).

Hernández y Solano (2007) anotan características que lo diferencian de otras formas de acoso:

- Exige el dominio y el uso de las TIC.

- Se trata de una forma de acoso indirecto.

- Es un acto de violencia camuflada, en la que la persona agresora es una total desconocida, a no ser que haya sido hostigadora presencial de la víctima antes o que decida serlo después del ciberbullying.

- El desconocimiento la persona agresora [engrandece] el sentimiento de impotencia.

- Recoge diversos tipos o formas de manifestar el acoso a través de las TIC.

- Desamparo legal de estas formas de acoso, ya que aunque se puede cerrar la web, inmediatamente puede abrirse otra.

- El acoso invade ámbitos de privacidad y aparente seguridad como el hogar, [la familia y los estudios], por lo que desarrolla un sentimiento de desprotección total.

- El acoso se hace público, se abre a más personas rápidamente (Hernández y Solano, 2007, pp. 24-25).

Buelga et al. (2010) recurren a Kowalski y Limber, y Olweus para explicar que en el ciberbullying, al igual que en el acoso escolar, "la intencionalidad, la repetición de la conducta dañina y el desequilibrio de poder entre el agresor y la víctima" también prevalecen (p. 784).

Calmaestra (2011) apela a las características que Olweus le asigna al bullying, para referirse a que ciberbullying es intencionado; perdurable en el tiempo y con un desequilibrio de poder entre la persona agresora y la víctima; pero le adiciona el anonimato; se propaga en contextos públicos y privados; y emplea un canal de comunicación abierto, que incluye perversión moral, con exiguo contacto físico y social entre los sujetos partícipes.

El anonimato es una de las características reforzadas por del Rey et al. (2011), ya que, en su opinión, agrava los efectos del acoso. Los sujetos que agreden, los que son víctimas y las demás personas que están involucradas pueden ignorar quiénes son con los que han generado este tipo de relaciones y, agregan estos autores, que el acoso se repetirá y se prolongará en el tiempo, debido a que el sujeto acosador podría emitir la acción una sola vez, en tanto que la víctima seguirá siendo acosada interminablemente dadas las características del medio empleado para dañar. 
doi: http://doi.org/10.15359/ree.24-1.3

URL: http://www.una.ac.cr/educare

CORREO: educare@una.cr

Según Kowalski et al. (2010), los principales medios empleados por los sujetos perseguidores para acosar electrónicamente a sus pares son la mensajería instantánea, el correo electrónico, los mensajes de texto, las redes online, chats, blogs, páginas web y los videojuegos.

Partiendo de lo anterior, es importante hacer referencia específica a las formas en que el ciberbullying se hace evidente. Como más adelante se verá, muchas de estas formas que surgen de la recopiliación bibliográfica, son las que lleva a cabo el estudiantado que participó de esta investigación.

\section{Formas en que se manifiesta el Ciberbullying}

Investigaciones como las de Collell y Escudé (2008), Ferro (2014), Flores y Casal (2008), Luengo (2014), Molina y Vecina (2015) coinciden en señalar que las formas como se pone en práctica el ciberbullying son:

- Enviar a una persona con frecuencia mensajes que ofenden, hostigan e insultan (Collell y Escudé, 2008; Luengo, 2014; Molina y Vecina, 2015).

- Realizar confrontaciones en línea, utilizando un vocabulario maleducado y mordaz, a través del chat, los mensajes de texto, la red social, entre otros (Collell y Escudé, 2008; Luengo, 2014).

- Circular habladurías sobre la víctima, de manera que las personas que leen, responden con malos tratos o situaciones de acoso contra la persona perjudicada (Flores y Casal, 2008; Luengo, 2014; Molina y Vecina, 2015).

- Pretender ser alguien que no se es y envía o difunde materiales o información online que deja mal a la persona acosada, la pone en riesgo y daña su integridad ante otras personas (Luengo, 2014).

- Gabar acciones sexuales con el teléfono celular y al enviarlo a la pareja, esta última lo envía a sus amistades con el propósito intencional de ofender y agraviar a la otra persona (Luengo, 2014).

- Robar la contraseña de la víctima para suplantar su identidad (Collell y Escudé, 2008; Ferro, 2014; Luengo, 2014; Molina y Vecina, 2015).

- Realizar llamadas en horarios inadecuados desde la telefonía móvil o cualquier teléfono fijo, al móvil de la víctima. El sujeto acosador llama y cuelga sucesivamente de manera que interrumpe, amenaza, insulta, grita, asusta y aterroriza constantemente a la víctima (Ferro, 2014; Flores y Casal, 2008).

- Cuelga en internet una imagen comprometida (real o montada) o datos que pueden perjudicar o avergonzar a la víctima y los da a conocer a todos sus contactos (Collell y Escudé, 2008; Flores y Casal, 2008). 
- Crear página web donde se puntúa o se da votos al compañero de clase "más tonto", "más feo", "más gordo", entre otros, para que aparezca en primer lugar (Collell y Escudé, 2008; Ferro, 2014; Flores y Casal, 2008).

- Crear un espacio o perfil falso en nombre de la víctima, en la cual comparte intimidades o hace demandas explícitas en materia sexual (Collell y Escudé, 2008; Flores y Casal, 2008).

- Dar de alta en determinados sitios la dirección de correo electrónico de la víctima para que sus mensajes se etiqueten como spam en la lista de contactos (Flores y Casal, 2008).

Al respecto, Castro y Reta (2013) exteriorizan que, independientemente del tipo de acoso y la manifestación que se emplee, cuando se hacen las publicaciones digitales, se salen del control personal de forma permanente. Estas formas en las que el ciberbullying se manifiesta, son ejecutadas y recibidas por diferentes actores, el siguiente apartado hace alusión a esto.

\section{Actores que intervienen en el ciberbullying}

Como bien se sabe, en una situación de agresión hay, al menos, dos personas involucradas: la que recibe la agresión y la que la hace. ¿Cuáles son las características de estas personas y de qué forma actúan? Molina y Vecina (2015) plantean que existen las personas acosadoras y las personas víctimas. En ambos casos y siguiendo con los autores citados, se habla de una intervención directa o indirecta.

De este modo, se puede afirmar que la persona acosadora directa es la que realiza las acciones cara a cara y de manera violenta contra la víctima; mientras que la persona acosadora indirecta es la que incita a las demás para llevar a cabo la agresión, la planea y la organiza (Molina y Vecina, 2015).

Por otra parte, en cuanto a la persona acosada, los estudios citados también hablan de personas acosadas activas y personas acosadas pasivas. Las primeras, ante las continuas y persistentes provocaciones, reaccionan y actúan de forma desafiante y a la defensiva (Molina y Vecina, 2015). Las segundas, sufren continuas vejaciones y acciones de persecución por parte del sujeto acosador. La reacción es sumisa, no se defienden (Molina y Vecina, 2015).

Finalmente, es necesario hacer alusión a los sujetos espectadores, que son las personas que están presentes o que se involucran en las acciones violentas emitidas por quien acosa. Los roles que en opinión de Molina y Vecina (2015) desempeñan las personas espectadoras son los siguientes:

- Personas seguidoras o cómplices del sujeto agresor: ayudan a la persona agresora, siendo implicados de una forma directa en la agresión (Molina y Vecina, 2015).

- Personas reforzadoras pasivas: presencian las conductas violentas y son conscientes del daño causado a la víctima, pero no hacen nada por evitar la situación (Molina y Vecina, 2015). 
doi: http://doi.org/10.15359/ree.24-1.3

URL: http://www.una.ac.cr/educare

CORREO: educare@una.cr

- Personas observadoras: exclusivamente observan lo que sucede (Molina y Vecina, 2015).

- Personas defensoras de la víctima: apoyan y defienden a la parte acosada, ya sea directamente; interponiéndose entre el sujeto acosado y el acosador con el propósito de que este último y sus cómplices cesen el hostigamiento, o buscando ayuda externa de una persona adulta (sea docente, compañero o compañera, personal de jefatura, entre otras) (Molina y Vecina, 2015).

Teniendo claro un panorama amplio sobre las personas involucradas en el ciberbullying, se considera relevante mencionar lo relacionado con el desarrollo socioemocional y este fenómeno social, en tanto, tal como se verá en los resultados de la investigación, es el aspecto que más implicaciones tiene.

\section{Consecuencias emocionales del ciberbullying}

En lo que concierne al impacto que el Ciberbullying tiene en el desarrollo emocional de la víctima, Garaigordobil (2011) señala que el daño emocional como consecuencia de este es muy significativo, debido a que la información perniciosa está accesible para todas las personas las veinticuatro horas del día y durante largos períodos de tiempo. Además, el acoso es anónimo, lo que lo hace continuo e inevitable y difícil de eliminar el material publicado, razón por la que la víctima tiende a experimentar ansiedad, depresión, ideación suicida, estrés, miedo, inseguridad, indefensión, nerviosismo, irritabilidad, emociones relacionadas con la ira, la frustración, trastornos somáticos y del sueño y dificultades para concentrarse por lo que se afecta su rendimiento académico.

Feinberg y Robey (comentados por Garaigordobil, 2011) son del criterio de que las personas adolescentes son más vulnerables ante esta problemática, ya que se muestran reacias a conversar, acerca del abuso que están soportando, con las personas adultas que les rodean, situación que a todas luces aumenta el trauma emocional. Además tienden a pensar que lo que les acaece es por su culpa, que no pueden decirlo por sospecha a una eventual revancha por parte del sujeto acosador o por intranquilidad ante el hecho de que se les limite el uso de internet o del teléfono móvil. Agregan los estudios que el aspecto emocional se afecta sustancialmente ante las amenazas graves contra la integridad de la víctima, las que podrían conducirla al suicidio cuando ya no posea la capacidad para soportar más sufrimiento y, en su punto más extremo, desencadenar en violencia juvenil.

Cruz (2011) plantea que los efectos sociales del ciberbullying en la víctima se caracterizan por la presencia de actitudes de desconfianza hacia sus pares; tendencia al aislamiento, evitación y retraimiento; sentimientos de incomprensión en las relaciones familiares; abandono de responsabilidades y compromisos familiares y dificultades para manifestar el afecto. 
Agregan del Río et al. (2010) que las agresiones que realiza la persona agresora mediante las tecnologías conllevan a que las víctimas tengan repercusiones en su salud mental y física, tales como problemas de alimentación, abandono del hogar, depresión, notas bajas y conductas violentas o suicidas.

Por su parte, Vega (2016, citando a Bhattacharjea) describe que las consecuencias psicológicas en la víctima podrían estar relacionadas con la tendencia a culparse a sí misma, a experimentar vergüenza e impotencia por lo que le está ocurriendo, a sentir un miedo constante, a aislarse y preferir estar en soledad, a minimizar la situación de acoso, a sentir que no tiene el poder suficiente por lo que se muestra sumisa, a descuidar su aspecto, a estar en estado de confusión, a depender de la aprobación de otras personas y a deprimirse.

Otras consecuencias emocionales descritas por esta autora son el déficit de autoestima, un retroceso en el desarrollo de las habilidades, crisis de ansiedad, ausencia de amistades con quienes compartir, quejas psicosomáticas, inestabilidad emocional, baja autoestima, bajo rendimiento escolar y sentimiento de impotencia y suicida, entre otros.

En el caso de las víctimas, en opinión de Hinduja (citado por Vega, 2016), conforman dos grupos, por una parte el que refiere no sentirse afectado por las agresiones de que son objeto y el otro que a todas luces da cuenta de su enfadado o tristeza constante ante la situación que está viviendo.

Así las cosas, Vega (2016) plantea que los sentimientos que la víctima experimenta ante el ciberbullying estarán determinados por el tipo de agresión, el impacto de esta en la cotidianidad, la lectura que se haga acerca de la agresión y el perfil emocional de la víctima.

\section{El camino metodológico para escuchar la opinión de adolescentes}

\section{Tipo de investigación}

Para poder cumplir con el objetivo general esbozado, esto es, "conocer el impacto del ciberbullying en el desarrollo socioemocional de adolescentes de $7^{\circ}, 8^{\circ}, 9^{\circ}, 10^{\circ}$ y $11^{\circ}$ año, de cuatro colegios de las provincias de San José y Heredia, así como las posibles maneras de enfrentarlo y prevenirlo", se propuso realizar una investigación con un enfoque mixto, (cualitativo y cuantitativo), fundamentados en el hecho de que no son excluyentes y no se sustituyen, ya que los dos se integran. Además, cada uno de los enfoques cumple con una tarea determinada, lo que a todas luces propicia el conocer y comprender el fenómeno social que se está estudiando (Hernández, Fernández y Baptista, 2003).

Con base en lo antes anotado y desde el enfoque cuantitativo, vale decir que el estudio se caracteriza por ser de tipo descriptivo, en razón de que mediante las respuestas aportadas por las personas participantes en la investigación, es factible realizar conclusiones en torno a la influencia que tiene el acoso cibernético en el desarrollo socioemocional del estudiantado adolescente (Hernández et al., 2003). 
doi: http://doi.org/10.15359/ree.24-1.3

URL: http://www.una.ac.cr/educare

CORREO: educare@una.cr

La valía de este aporte radica en que reúne datos que ponen en evidencia un evento, un fenómeno o un hecho acontecido en un determinado contexto (Hernández et al., 2003), es decir, ofrece una perspectiva lo más real posible acerca del acoso cibernético que podría estar enfrentado la población adolescente en los centros educativos y, a partir de ello, realizar las acciones pertinentes. Desde el enfoque cualitativo, se busca acceder al grupo de participantes de "manera personal e identificar sus propias definiciones del mundo, tomadas con las propias palabras de las personas, habladas o escritas, y según la conducta observable" (Taylor y Bodgan, 1992, p. 73).

\section{Población meta}

Las personas que formaron parte de la investigación realizada en el Instituto de Estudios Interdisciplinarios de la Niñez y la Adolescencia (INEINA)"Ciberbullying: conociendo su impacto en el desarrollo socioemocional de la población adolescente y reflexionando acerca de posibles formas de prevenirlo", fue el estudiantado de sétimo a undécimo año, tres personas que dirigen las instituciones, el personal docente y las figuras parentales de cuatro centros educativos públicos y privados, ubicados en la provincia de Heredia y San José.

El criterio de selección de los centros educativos participantes fue intencional, partiendo del principio de conveniencia, ya que eran centros educativos con los cuales el INEINA tenía vínculos y contactos dispuestos a colaborar.

Se considera necesario reiterar que, aunque en la investigación citada anteriormente participaron diferentes poblaciones, para efectos de este artículo, únicamente se toma en cuenta lo concerniente a la población estudiantil, debido a que por la amplitud de este estudio las autoras consideraron relevante publicar la información separando las poblaciones, con el propósito de profundizar en cada una de las poblaciones participantes. En cada colegio se trabajó con un grupo de estudiantes de sétimo a undécimo. Los centros educativos que conforman la muestra son: San José de La Montaña, COOPECOCEIC, La Palabra de Vida y el centro educativo Santa Cecilia.

En total participaron 447 estudiantes, 269 de sétimo a noveno año y 178 de décimo y undécimo año. Cabe agregar que esta población se dividió en 142 hombres y 126 mujeres de sétimo a noveno año (con edades entre 12 y 18 años), así como 80 hombres y 98 mujeres de décimo y undécimo año (con edades entre 16 y 19 años).

Es importante destacar que se separó al estudiantado en dos niveles (de sétimo a noveno y de décimo a undécimo) porque en un inicio se consideró que al tratarse de edades diferentes, las respuestas podían variar de un nivel a otro, sin embargo, no fue así, hay mucha coincidencia entre lo que plantea el estudiantado de un nivel y del otro.

\section{Instrumentos}

Para la recolección de los datos se destinó un instrumento dirigido a la población adolescente, basado en preguntas abiertas y cerradas, cuya finalidad era conocer el impacto que 
el ciberbullying tiene en el desarrollo socioemocional del estudiantado de sétimo a undécimo año. Este instrumento fue aplicado por las personas responsables del proyecto de investigación en cada una de las instituciones participantes.

\section{Tipo de análisis}

El impacto que el acoso cibernético tiene en el desarrollo social y emocional de las personas menores de edad se debe a una gama diversa de factores de riesgo y causas, por lo que se consideró la necesidad de investigar la temática tanto cuantitativa como cuantitativamente, en aras de poder contar con una visión lo más real posible del problema. Por ello, la investigación trata de integrar datos cualitativos y cuantitativos, los cuales, mediante las variables y categorías emergentes de análisis, permitan cumplir los objetivos específicos formulados en la investigación.

En virtud de lo antes expuesto, cabe pensar que desde una representación cualitativa, el método de análisis empleado es el fenomenológico, en tanto busca estudiar el significado de la experiencia humana tal y como lo han vivenciado las personas que colaboraron. Esto es consecuente con la opinión de Buendía, Colás y Hernández (1999), acerca de que la descripción de cada experiencia que tiene la persona sobre un determinado fenómeno, favorece la reflexión y la concienciación de sus propios sentimientos; con la expresada por Sandín (2003), en cuanto a que el pensamiento fenomenológico favorece visualizar "experiencia subjetiva de los hechos tal y como se perciben" (p. 62) y con la de Buendía et al. (1999), quienes robustecen la creencia de que el análisis fenomenológico pone especial énfasis en las personas y su subjetividad, de ahí que guste de investigaciones cuya meta es describir los acontecimientos tal y como están registrados en el consciente de cada persona.

La información cualitativa está contenida textualmente en las tablas tal cual la manifestó la población consultada, por lo que no se corrigieron los errores ortográficos que se evidencian en muchas de las respuestas.

En el siguiente apartado se profundiza sobre las opiniones del estudiantado de sétimo a undécimo año, acerca de aspectos relacionados con el concepto de ciberbullying, estudiantado acosado, acosador, observador, impacto del ciberbullying en la vida personal de los adolescentes y las adolescentes, recomendaciones para las familias desde la voz del alumnado, entre otros aspectos.

\section{Las opiniones de la población adolescente: Lo que vivimos, vemos y hacemos}

Cuando como personas adultas nos detenemos a escuchar las opiniones y sentimientos de los adolescentes y las adolescentes, nos damos cuenta de que, a veces, de sus respuestas se desprenden "llamadas de alerta" y, en el caso particular de esta investigación, las autoras podemos afirmar que las opiniones del estudiantado reflejan las necesidades emocionales que 
doi: http://doi.org/10.15359/ree.24-1.3

URL: http://www.una.ac.cr/educare

CORREO: educare@una.cr

tienen, las situaciones problemáticas por las que están pasando, así como el tipo de vínculos que establecen con sus pares, figuras parentales y docentes, lo que podría implicar un llamado de atención para que las personas adultas revisen estos aspectos y fortalezcan los vínculos y las relaciones que establecen con los grupos de adolescentes.

A continuación se describen las opiniones más relevantes de estudiantes en cuanto al ciberbullying. Es importante destacar que las respuestas brindadas están entre comillas, anotadas tal y como las escribieron e incluidas las faltas de ortografía.

\section{Nuestras familias y los vínculos que formamos con ellas}

El $68 \%$ del estudiantado de $7^{\circ}, 8^{\circ}$ y $9^{\circ}$ y un $74.7 \%$ de $10^{\circ}$ y $11^{\circ}$ viven con su madre, padre, hermanas y hermanos; mientras que el $16.7 \%$ de tercer ciclo viven únicamente con su madre y con su mamá y hermanos o hermanas el 15.7 \% de Educación Diversificada.

Las personas en las que más confía el estudiantado de III ciclo son la mamá (23,9\%), los amigos o amigas (19,8\%), familiares como abuelos, abuelas, tías, tíos, primas o primos (14,5 $\%)$ y el papá (13.7\%). El estudiantado de $10^{\circ}$ y $11^{\circ}$ confía más en la madre (26\%), amigos o amigas (24,3\%), hermanos o hermanas $(15,4 \%$ ) y el papá $(13,4 \%)$. Es evidente la coincidencia en las respuestas brindadas entre ambos niveles de estudiantes, pudiéndose inferir el papel tan significativo que tiene la mamá en la vida del hijo o hija, independientemente de la edad que tengan, así como que el vínculo de confianza que establecen con la figura paterna no es tan sólido como el materno, ya que incluso ubican a los amigos, amigas, hermanas, hermanos y otras personas familiares antes que a sus papás.

Al respecto la UNICEF (2002) destaca:

Al establecer lazos coherentes, positivos y emocionales con adultos responsables, los jóvenes pueden sentirse seguros y a salvo, y obtener la resistencia que les permita confrontar y resolver los problemas que les depare la vida. Un estudio llevado a cabo con niños de 14 años de Estados Unidos, Australia, Colombia, la India, Palestina y Sudáfrica descubrió, por ejemplo, que en todas las culturas los adolescentes que tienen relaciones estrechas con sus padres y madres (es decir, que se sienten entendidos, reciben buenos cuidados y se llevan bien con ellos) tienen mayor iniciativa social, abrigan menos ideas de suicido y sufren menos depresión. (p. 9)

\section{Lo que conocemos sobre el ciberbullying...}

Una mayoría de estudiantes de ambos ciclos ( $73.7 \%$ de III y $75.3 \%$ de Diversificada), manifiesta que sí conoce sobre este fenómeno, y destacan respuestas como: 
"Cuando se insulta o se burla a otra persona por medio de la Internet". "Acosar o molestar a alguien por medio de la tecnología en especial el Internet". "Son formas de abuso, amenaza y hostigamiento por redes sociales principalmente". "Ofensas e intentar humillar una persona como lo haría un brabucón, pero en el internet". "Cuando se dice, ofende o se critica o hace la vida miserable a alguien medianteelinternet." "Es ofender a una persona por redes sociales (ofenderde manera muy elevada)".

Nótese que el estudiantado en su mayoría tiene claridad acerca del término $C B$, ya que como lo plantea Mora-Merchán (citado por Ferro, 2014, p. 65) el ciberbullying es "cualquier forma de agresión intencional y repetitiva que genera abusos de poder a través de las nuevas tecnologías, como el correo electrónico, los chats, los móviles o las redes sociales", entre otros.

\section{Los medios tecnológicos y cibernéticos que usamos}

En relación con el momento en que el estudiantado utiliza los medios tecnológicos y cibernéticos en el colegio, se tiene que lo hacen mientras están en clase, sin que el profesorado se dé cuenta, $15.1 \%\left(7^{\circ}, 8^{\circ}\right.$ y $\left.9^{\circ}\right)$ y $21,2 \%\left(10^{\circ}\right.$ y $\left.11^{\circ}\right)$. Además, manifiestan que nadie supervisa el uso de estos medios cuando están en el colegio ( $34.5 \%$ de $7^{\circ}, 8^{\circ}$ y $9^{\circ}$ y $49.7 \%$ de $10^{\circ}$ y $11^{\circ}$ ). Tampoco reciben supervisión en la casa según el $40.5 \%$ de III ciclo y el $71.8 \%$ de $10^{\circ}$ y $11^{\circ}$ y pueden utilizar estos medios en la casa cuando lo deseen el $82.8 \%$ de $7^{\circ}, 8^{\circ}$ y $9^{\circ}$ y el $93.8 \%$ de $10^{\circ}$ y $11^{\circ}$ niveles. Al respecto, del Rey et al. (2011) señalan que existen determinadas prácticas de riesgo y algunos indicios que, de observarse adecuadamente, pueden llevar a sospechar que se está en presencia de un caso de CB. Uno de estos criterios es la falta de supervisión de las figuras parentales acerca del uso de las TIC. Es alarmante percibir que, tanto en el colegio como en la casa, principalmente, el estudiantado manifiesta que no está siendo supervisado por las personas adultas.

\section{Los que vivimos el ciberbullying}

Al preguntar a la población estudiantil, si están siendo acosada, maltratada o ridiculizada a través de los medios tecnológicos, un $23.7 \%$ de $7^{\circ}, 8^{\circ}$ y $9^{\circ}$ manifiesta que sí, y un $16.9 \%$ de $10^{\circ}$ y $11^{\circ}$ años. Los medios por los cuales se les acosa más son el Facebook, los mensajes de texto y las llamadas telefónicas. Precisamente, Ferro (2014) destaca que los medios a través de los cuales se produce el ciberacoso incorporan artefactos tecnológicos utilizados con mayor frecuencia por la juventud, por ejemplo: mensajes, redes sociales, celulares, chat, entre otros.

Otros datos relacionados con la población estudiantil que dijo ser acosada revelan que para el estudiantado de $7^{\circ}$ a $9^{\circ}$ años, ha durado menos de un mes (57.8\%), de uno a tres meses (18.7 \%) y de seis meses a un año (6.2\%). Además, argumentan que varias mujeres fuera del colegio son, en su mayoría, las que realizan este acoso, lo que evidencia que saben quién les está acosando. En los niveles de $10^{\circ}$ y $11^{\circ}$ años apuntan que el acoso ha durado, menos de un mes $(46.7 \%)$, de uno a tres meses ( $26.7 \%$ ) y de tres a seis meses ( $10 \%)$. Agregan que mayoritariamente el acosador es un hombre que está fuera del colegio. Se evidencia nuevamente que conocen quién los acosa y en dónde se encuentra esa persona. 
doi: http://doi.org/10.15359/ree.24-1.3

URL: http://www.una.ac.cr/educare

CORREO: educare@una.cr

Cuando se le consultó al estudiantado si "¿contó a alguien sobre su situación de acoso?", un $66.6 \%$ de $7^{\circ}$ a $9^{\circ}$ manifiesta que sí y un $80 \%$ de $10^{\circ}$ y $11^{\circ}$ años también respondió afirmativamente a esta pregunta. El porcentaje de estudiantes que expresó no haber contado sobre su situación de acoso brindó diferentes respuestas, entre las que sobresalen: "No era nada que me afectara". "No vale la pena, es solo por molestar, llamar la atención". "No es lo suficientemente importante como para dedicarle tiempo". "Porque no me hacen un ciberhurirg tan duro entonces no le doy importancia". "Porque no es la gran cosa decirle a alguien".

Según el estudiantado, las formas en las que principalmente ha sido acosado son tres: "Han contado mentiras o chismes falsos sobre mí por medio del celular o Internet". "Me llaman constantemente por el celular y no contestan cuando respondo" y "Me han enviado o han colgado en la red, rumores sobre mí para dañar mi reputación". Es importante aclarar que el estudiantado de todos los niveles consultados consideró estas tres formas de acoso, como las principales, de un listado que se les brindó en el instrumento.

Al examinar a la juventud acerca de: ¿cuál es el impacto de estos acosos y maltratos cibernéticos en su vida personal?, dio diferentes respuestas. En la Tabla 1, se muestran las principales con sus porcentajes y agrupadas en categorías según el nivel, sin embargo, es evidente que existe congruencia entre ambos grupos de estudiantes.

Tabla 1: Impacto del acoso cibernético en la vida personal, según opinión de la población adolescente

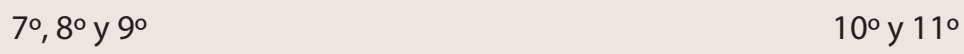

No le afecta (42.1\%): "me da igual", "las dejo pasar, no les tomo importancia", "no me afecta en nada porque es para hacer sentir mal y yo se las intenciones y no les doy importancia"

Afecta emocionalmente (35.9\%): "bastante pues creía mi vida terminada, no quería ser humillada por las amenazas", "me sentía un poco triste", "me siento ridiculizada".

Siente miedo y desconfianza (7.8\%): "a veces me da miedo quedarme sola o salir", "me intimidan un poco", "en que uno se asusta"
No le afecta (50\%): "De ninguna manera, no me hace efecto". "No influyeron mucho en nada". "No me afecta muy seguido".

En la autoestima (23.5\%): "el autoestima", "Es feo que hablen de uno y siempre logran bajar un poco la autoestima".

Siento temor (10\%): "Me dan temor". "A veces duele y asusta pero depende de lo que sea sigo adelante y me defiendo".

Nota: Elaboración propia con base en el cuestionario para estudiantes de sétimo a undécimo años, empleado en la investigación de Morales, Chaves y Villalobos (2016). 


\section{Lo que hicieron las personas adultas ante las situaciones de acoso}

La población estudiantil de todos los niveles manifiesta en su mayoría que las familias no tomaron ninguna acción para evitar el maltrato y acoso cibernético que sufrieron ( $38.2 \%$ de 70 a $9^{\circ}$ y $45.8 \%$ de $10^{\circ}$ y $11^{\circ}$ ). Con porcentajes menores mencionan que la familia realizó acciones como aconsejar y apoyar, restringir el uso de los medios tecnológicos, hablar con las personas involucradas, protegerles y supervisar el uso de los medios tecnológicos. Adicionalmente, un $32.4 \%$ de $7^{\circ}$ a $9^{\circ}$ dijo que el colegio no hizo nada en su caso de acoso y un $46.6 \%$ de décimo y undécimo años, opinó lo mismo.

Lo que más preocupa de estos datos es, precisamente, que estas acciones, que evidencian algún tipo de apoyo para el estudiantado, son las que menos porcentajes tienen y, por lo tanto, son las que menos realizan tanto las figuras parentales como el equipo docente del colegio. Cabe preguntarse, entonces, ¿cuál es la responsabilidad de las personas adultas y cuáles son vínculos que están estableciendo con las personas adolescentes?

\section{Los que conocemos del maltrato a nuestros compañeros y amigos}

Al estudiantado de secundaria, también se le preguntó si conocían acerca de casos en los que personas amigas o compañeras, fueran acosadas por medios tecnológicos y cibernéticos. Un porcentaje significativo, tanto de estudiantes de sétimo a noveno (37.5\% equivalente a 101 estudiantes), como de décimo y undécimo (37.7\% equivalente a 67 estudiantes), manifestó que sí. Al mismo tiempo se investigó si habían contado sobre estos casos de acoso de sus pares y las respuestas que brindaron se muestran en la Tabla 2.

Tabla 2: Estudiantes que conocen acerca de maltratos y acosos cibernéticos de sus pares

\begin{tabular}{lccl}
\hline \multicolumn{1}{c}{ Estudiantes } & Sí contó & No contó & Razones por las que NO contó \\
\hline Sétimo a noveno & $63.3 \%$ & $36.6 \%$ & "No me importa". "No es amigo cercano". “Ya todos sabían”. \\
Décimo y undécimo & $44.8 \%$ & $55.2 \%$ & $\begin{array}{l}\text { "No es mi problema". "No me interesa". "Para no aumentar la } \\
\text { humillación". }\end{array}$ \\
\hline
\end{tabular}

Nota: Elaboración propia con base en el cuestionario para estudiantes de sétimo a undécimo años, empleado en la investigación de Morales et al. (2016).

Estos resultados reflejan que sí hay conocimiento por parte del estudiantado de los maltratos y agresiones hacia sus pares; no obstante, no hacen nada para evitar, minimizar o prevenir estos abusos. Al respecto, es importante destacar que las personas que están presentes o que se involucran en las acciones violentas emitidas por el sujeto acosador se llaman espectadoras. Molina y Vecina (2015), plantean que los sujetos espectadores pueden desempeñar diferentes roles. Dos de los que se evidencian en las respuestas adolescentes son: los reforzadores pasivos, quienes presencian las conductas violentas y son conscientes del daño causado a la víctima, pero no hacen nada por evitar la situación. Y los sujetos observadores, 
doi: http://doi.org/10.15359/ree.24-1.3

URL: http://www.una.ac.cr/educare

CORREO: educare@una.cr

quienes exclusivamente observan lo que sucede (Molina y Vecina, 2015). Es preocupante, que existan grandes porcentajes de estudiantes que asuman estas situaciones con una actitud pasiva y que no intervengan. Sin duda alguna, esta falta de acción y de sensibilidad de parte de las amistades y pares de clase de la población acosada también influye y hace que el fenómeno no se detenga, sino que continúe.

\section{Sí, yo soy una persona acosadora}

Interesó preguntar al estudiantado de sétimo a undécimo años, si ellos y ellas habían agredido, maltratado o ridiculizado a sus pares utilizando los medios tecnológicos y cibernéticos, los datos que surgieron de esta pregunta se observan en la Tabla 3.

Tabla 3: Estudiantes que acosan y maltratan a través de medios tecnológicos

\begin{tabular}{cccc}
\hline \multicolumn{1}{c}{ Estudiantes } & Sí & No & No responde \\
\hline Sétimo, octavo y noveno & $11,1 \%$ & $86,9 \%$ & $1,8 \%$ \\
Décimo y undécimo & $10,1 \%$ & $89,9 \%$ & $0 \%$ \\
\hline
\end{tabular}

Nota: Elaboración propia con base en el cuestionario para estudiantes de sétimo a undécimo años, empleado en la investigación de Morales et al. (2016).

Si bien, de los resultados anteriores se desprende que la mayoría de las personas estudiantes manifiesta no ser acosadoras, hay un porcentaje que afirma sí serlo y esto es preocupante. Cuando se les consulta la razón por la cual acosan o han acosado a sus compañeros, compañeras o amigos y amigas responden lo que se muestra en la Tabla 4.

Tabla 4: Razones por las que acosan y maltratan a través de los medios tecnológicos

\begin{tabular}{cl}
\hline Estudiantes & \multicolumn{1}{c}{ Ejemplos de respuesta } \\
\hline Sétimo, octavo y noveno & "Di, lo hago en juego con un amigo". "No se, simplemente xq es vacilón joder". "Porque \\
me lo hicieron a mi". "Se habían burlado de mi". "Porque ellos se lo buscan". "Porque me & cae mal". "Porque era muy estúpido". "No lo se me hacia sentir bien". "Porque todos lo \\
& hacían". "Para que no me lo agan". \\
& "Por diversión". "Porque es jodiendo". "Para llamar la atención". "Porque ella les caía \\
Décimo y undécimo & "Porque son bromas menores entre amigos que no pasan a más". "X la joda". "No es \\
& muy grave, molesto a mis amigos".
\end{tabular}

Nota: Elaboración propia con base en el cuestionario para estudiantes de sétimo a undécimo años, empleado en la investigación de Morales et al. (2016). 
Las respuestas anteriores, revelan según Castro y Reta (2013), que los sujetos acosadores no siempre tienen conciencia del daño psicológico que producen a la víctima, como bien se puede observar, muchas de las respuestas del estudiantado hacen alusión a que lo hacen por broma, por molestar y por divertirse. De esto se puede inferir que ellos o ellas lo toman como algo sin importancia. Asimismo, de las respuestas que brindan estas personas adolescentes en particular, se pueden inferir características propias del rol de la persona acosadora como que tienen un déficit de autoestima, la cual se ve fortalecida cuando desempeñan un rol dominante y de control sobre sus pares (Molina y Vecina, 2015). Se agrega que tienen baja tolerancia a la frustración, motivo por el cual son personas impulsivas a la hora de reaccionar (Molina y Vecina, 2015). Además, parecen ser duras y demuestran escasa empatía por sus pares que están siendo acosados o acosadas (Olweus, citado por Kowalski et al., 2010).

\section{¿Por qué creemos que se da el acoso, maltrato y humillación a otros?}

A la población adolescente también se le consultó acerca de las razones por las que creen que hay compañeros y compañeras que acosan, maltratan y humillan a otras personas a través de los medios tecnológicos y cibernéticos. Las principales categorías de las respuestas que brindan están en la Tabla 5 (Ordenadas de mayor a menor porcentaje).

Tabla 5: Razones por las que se da el acoso, maltrato y humillación a las demás personas, mediante la tecnología

\begin{tabular}{ll}
\hline \multicolumn{1}{c}{ Sétimo octavo y noveno } & Décimo y undécimo \\
\hline Porque se sienten superiores/para llamar la atención & Por problemas emocionales \\
Por envidia, venganza, celos y rencor & Por diversión \\
Porque tienen problemas emocionales & Por llamar la atención \\
Porque no quieren o no se atreven a decirlo de frente & Por problemas familiares \\
Por diversión & Por envidia y celos \\
Para molestar & Porque es anónimo \\
Para hacer el daño & Para sentirse bien \\
Porque les cae mal & Porque les cae mal \\
\hline
\end{tabular}

Nota: Elaboración propia con base en el cuestionario para estudiantes de sétimo a undécimo años, empleado en la investigación de Morales et al. (2016). 
doi: http://doi.org/10.15359/ree.24-1.3

URL: http://www.una.ac.cr/educare

CORREO: educare@una.cr

Las respuestas del estudiantado permiten concluir que tienen claridad del por qué se da la agresión cibernética entre pares y se evidencia que estas razones giran en torno a situaciones socioemocionales que afectan a la persona acosadora. Las categorías permiten ver un perfil de sujeto acosador que tiene déficit en su autoestima, no puede controlar la ira (Molina y Vecina, 2015), evade las situaciones para no resolverlas, se frustra con gran facilidad, le gusta afirmarse valiéndose de la fuerza (Olweus, citado por Kowalski et al., 2010) y que hay una gran influencia familiar en estas actitudes (Molina y Vecina, 2015).

\section{Escuchen nuestras recomendaciones...}

Al final del cuestionario, se le pidió al estudiantado que dieran recomendaciones a las familias, para que los hijos o hijas no sean víctimas de acoso cibernético. A continuación, un resumen de algunas de las respuestas brindadas.

\section{Estudiantes de $7^{\circ}, 8^{\circ}$ y $9^{\circ}$}

"Tener comunicación con los hijos". "Que les pregunten cómo les fue en el colegio". "Que nos escuchen". "Hacerles pregunta de sus vidas". "Promover la aceptación de nosotros mismos y los demás". "No dejarlos utilizar redes sociales". "Restringir algunas páginas de la web". "Supervisar el uso de la tecnología".

\section{Estudiantes de $10^{\circ}$ y $11^{\circ}$}

"Que les ayuden a construir su autoestima". "Quiera a sus hijos". "Traer un ambiente de tranquilidad al hogar". "Saber más sobre la vida de sus hijos". "Tener mayor comunicación con ellos". "Escuchen y pregunten, no solo griten". "Tener control sobre el uso de redes sociales". "Tener horarios y controlar su uso"

Las respuestas anteriores y otras que dio la población encuestada se organizaron en diferentes categorías, y como bien puede apreciarse, estas respuestas tienen que ver con brindar apoyo, protección y afecto; prestar atención al comportamiento de los hijos e hijas; comunicarse con los hijos e hijas y, entre otros aspectos, supervisar el uso de la tecnología. Sin duda alguna esta información refleja "llamadas de atención y auxilio" de parte de la población adolescente con respecto a las carencias emocionales que tienen en sus casas o que saben que están viviendo sus pares y, también, en cuanto a lo que para su generación resulta importante en las relaciones que establecen con sus padres y madres, por ejemplo: el afecto, el amor, el sentirse importantes y el sentir que se preocupan de lo que les ocurra, que confían en ellos y ellas, y que hay una necesidad y claridad de tener límites y control por parte de las familias. Lo anterior tiene que ver con el planteamiento de del Rey, Casas y Ortega (citados por Vives, Sánchez, Orte y Macías, 2014), quienes indican que "el fortalecimiento parental y la mejora en las pautas de crianza se convertirá en un factor de protección esencial en la disminución del Ciberbullying" (p. 4). 


\section{Algunas reflexiones finales}

A continuación, se presentan las principales reflexiones que surgen de los hallazgos encontrados con respecto a la opinión del estudiantado del fenómeno del ciberbullying. Se incluyen interrogantes con la intención de propiciar el análisis y la reflexión en las personas lectoras que se relacionan con adolescentes, de manera que asuman la responsabilidad que les atañe en la prevención de estas problemáticas sociales que inciden en el tiempo en familia, los vínculos, el afecto, el tiempo de calidad, el diálogo sincero, la confianza, entre otros aspectos cruciales en la vida de las personas.

- En las familias, el rol materno sigue jugando un papel fundamental en la vida del hijo o hija, ya que el $23,9 \%$ de III ciclo y el $26 \%$ de Diversificada confían más en ella, pero, qué está pasando con la figura paterna que no es considerada como una de las personas en las que más confían y cómo esto incide en las conductas y comportamientos del hijo o hija. Esto es lo que destaca el grupo de adolescentes, por lo tanto, su voz permite generar una reflexión en las figuras parentales sobre los tipos de vínculos que establecen con sus hijos e hijas y, con esto, sobre la necesidad de fortalecer su desarrollo socioemocional.

- Si la mayoría del estudiantado sabe lo que significa ciberbullying, por qué razón se sigue presentando este fenómeno entre adolescentes, o es que a lo interno de las familias y centros educativos no se reflexiona ni se sensibiliza acerca del impacto de este fenómeno social. De esto se desprende la necesidad de hacer un abordaje integral al ciberbullying, de modo que se generen interacciones familiares y educativas, más sanas y más respetuosas.

- La tecnología y redes sociales están siendo el común denominador en la vida de las personas adolescentes, quienes hacen un uso constante de estos medios sin el conocimiento ni supervisión de las figuras parentales, del personal docente o de las personas que dirigen las instituciones, sobre la forma, tiempo o espacios en los que están utilizándolos ( $34.5 \%$ de $7^{\circ}$ a $9^{\circ}$ y $49.7 \%$ de $10^{\circ}$ y $11^{\circ}$ ). Esto nos lleva a pensar una vez más sobre cuál está siendo la dinámica en las familias principalmente y de qué manera se están desarrollando social y emocionalmente las generaciones adolescentes.

- La mayoría del estudiantado acosado conoce dónde están y quiénes son las personas que les acosan, lo que hace pensar que adolescentes que dijeron estar sufriendo ciberbullying, en realidad está siendo víctima de bullying a través de los medios tecnológicos y cibernéticos, en razón de que se sabe cuál es la identidad del sujeto acosador; no se cumple, entonces, con la característica principal del ciberbullying: el anonimato. Resulta interesante cómo la población adolescente reconoce esta situación, lo cual refleja el tipo de interacciones que establecen con sus pares. De ello se desprende que estas personas menores de edad requieren de soporte emocional 
doi: http://doi.org/10.15359/ree.24-1.3

URL: http://www.una.ac.cr/educare

CORREO: educare@una.cr

para poder hacer frente a esto, en este sentido, el papel de las personas adultas que acompañen, contengan y establezcan vínculos sanos y positivos es fundamental.

- Los principales medios empleados para acosar son el Facebook, los mensajes de texto y las llamadas telefónicas, por lo que cabe reflexionar acerca del papel que ocupan las redes sociales en la vida de adolescentes y el rol que cumple al respecto, la persona adulta. Por otra parte, es importante preguntarse: ¿de qué manera esta conexión con la tecnología y las redes sociales impacta el desarrollo socioemocional de las personas adolescentes?, ¿cuál es el papel de las personas adultas al respecto?

- La mayoría del estudiantado que manifestó ser acosado opinó que este no tiene un impacto en suvida personal, lo que hace pensar en siesto es una negación de la afectación como defensa para sentirse fuertes y poder enfrentar estas dolorosas situaciones. Sin duda alguna, esto también refleja cuáles son las necesidades socioafectivas que tienen estos y estas adolescentes.

- Otras respuestas del estudiantado hacen alusión a un impacto negativo en el área socioemocional y tienen que ver con sentir temor, humillación, miedo, aislarse, tener dificultad para relacionarse con las demás personas e, incluso, experimentar ideas suicidas. De esta manera se puede concluir que las necesidades sociales y emocionales de adolescentes son fundamentales de abordar, pues de eso depende que se sientan bien consigo y con los demás seres, pero entonces qué está ocurriendo en las familias y centros educativos que pareciera no están haciendo nada al respecto.

- Resulta verdaderamente preocupante conocer, según la mayoría de las opiniones del estudiantado, que cuando han enfrentado situaciones de acoso cibernético, las personas adultas, ya sean figuras parentales o profesorado, no han hecho nada para protegerles del daño emocional que están sufriendo. Esto implica una reflexión sobre la responsabilidad que tienen las familias y el personal docente en el bienestar socioemocional de adolescentes a su cargo. Dichas situaciones de acoso, no pueden pasar desapercibidas por la población adulta responsable del estudiantado.

- Como se vio anteriormente, hay estudiantes que están asumiendo un rol pasivo en estas situaciones de acoso y maltrato a través de los medios tecnológicos y cibernéticos. Son estudiantes que conocen de maltratos a sus pares y amistades, y muchos no dicen nada acerca de esto. Ante esta realidad debe replantearse el concienciar al estudiantado acerca del rol tan importante que pueden desempeñar las personas observadoras en la prevención de esta problemática y erradicar las actitudes pasivas que legitiman este tipo de acoso, y cuestionar a las figuras parentales y docentes en relación con lo que están fomentando en las personas menores de edad para que asuman este tipo de actitudes. 
- Con respecto al estudiantado que acosa $(86,9 \%$ de III ciclo y $11,1 \%$ de Educación Diversificada), si analizamos las repuestas que brindan, en donde explican el por qué acosan a sus pares por medio de la tecnología, se desprende que hay grandes vacíos en este grupo, pues demandan ser atendidos, escuchados, amados, requieren vínculos de calidad, tiempo en familia, desean tener padres y madres presentes, que se fomente la empatía, la amistad y la tolerancia. Ante estas necesidades insatisfechas no queda más que preguntarse, si las conductas puestas en práctica por las personas adolescentes, son un reflejo de las dinámicas y vínculos que se establecen entre el estudiantado con las familias y el personal docente en los centros educativos, en cuyo caso parece urgente un cambio de actitud corresponsable.

- La prevención, abordaje y disminución del ciberbullying va mucho más allá de apagar una computadora, poner control al uso de internet, redes sociales o revisar un celular; tiene que ver con dinámicas que se están gestando en el interior de cada familia y centros de educación, la calidad y estrechez de los vínculos que se establecen, los espacios para compartir que tienen, las oportunidades de escuchar y ser escuchado que se dan y con raíces más profundas cuyo origen reside en las familias, entre otros relevantes elementos. De ahí que la interrogante que generamos es: ¿cuáles son los tipos de vínculos que estamos estableciendo en nuestras familias?, ¿qué tanto conocemos a nuestros hijos, hijas, estudiantes?, ¿qué tanto les escuchamos?, ¿se sienten amadas, protegidas y acogidas las personas adolescentes en las familias y escuelas?

- Ante el panorama anterior, dejamos, entonces, una primera "semilla" de reflexión plantada. La esperanza es que genere debate para autoevaluarnos en nuestro papel de personas adultas corresponsables no solamente en la crianza de adolescentes, sino en la prevención y abordaje eficaz y eficiente de problemáticas que conllevan al acoso de personas menores de edad, de manera que podamos tomar las medidas necesarias que fortalezcan nuestras relaciones e intervenciones en todos los ámbitos en los que cotidianamente nos relacionamos con esta población de muchachos y muchachas.

\section{Referencias}

Asamblea Legislativa de la República de Costa Rica. (27 de junio de 2016). Para la prevención y establecimiento de medidas correctivas y formativas frente al acoso escolar o bullying. La Gaceta Diario Oficial 138. Alcance n. ${ }^{\circ}$ 104. Recuperado de https://www.imprentanacional. go.cr/pub/2016/06/27/ALCA104 2706 2016.pdf

Buelga, S., Cava, M. J. y Musitu, G. (2010). Ciberbullying:victimización entre adolescentes a través del teléfono móvil y de internet. Revista Psicothema, 22(4), 784-789. Recuperado de http:// www.redalyc.org/articulo.oa?id=72715515039 
doi: http://doi.org/10.15359/ree.24-1.3

URL: http://www.una.ac.cr/educare

CORREO: educare@una.cr

Buendía, L., Colás, P. y Hernández, F. (1999). Métodos de investigación en psicopedagogía. Madrid: McGraw-Hill.

Calmaestra, J. (2011). Cyberbullying: Prevalencia y características de un nuevo tipo de bullying indirecto (Tesis doctoral). Universidad de Córdoba, Argentina. Recuperado de http:// helvia.uco.es/xmlui/bitstream/handle/10396/5717/9788469490976.pdf?sequence=1

Castro, A. (2013). Formar para la convivencia. Internet y prevención del ciberbullying. Integra Educativa, 6(2), 49-70. Recuperado de http://www.scielo.org.bo/pdf/rieiii/v6n2/v6n2a04.pdf

Castro, A. y Reta, C. (2013). Bullying blando, bullying duro y ciberbullying. Nuevas violencias y consumes culturales. Argentina: Homo Sapiens Ediciones.

Collell, J. y Escudé, C. (2008). No te enredes en la red. Guía para conocer el ciberbullying y algunos peligros de internet y las nuevas tecnologías. Recuperado de http://www.xtec.cat/ jcollell/ ZGuia\%20Ciber.pdf

Cruz, A. (2011).Elciberacoso:Causasy consecuencias [Foro]. Recuperado de http://congresoedutic. com/forum/topics/el-ciberacoso-causas-y

del Rey, R., Flores, J., Garmendia, M., Martínez, G., Ortega, R. y Tejerina, O. (2011). Protocolo de actuación escolar ante el ciberbullying. España: Equipo Multidisciplinar de investigación sobre el Ciberbullying.

del Río, J., Sádaba, C. y Bringué, X. (2010). Menores y redes sociales: De la amistad al Ciberbullying. Revista de Estudios de juventud, 88, 115-129. Recuperado de http://www.injuve.es/sites/ default/files/RJ88-09.pdf

Ferro, J. M. (2014). Acoso escolar a través de las nuevas tecnologías. Ciberacoso y grooming. Madrid: Editorial Formación Alcalá.

Flores, J. y Casal, M. (2008). Ciberbullying. Guía rápida para la prevención del acoso por medio de las nuevas tecnologías. Bilbao: ARARTECO Recuperado de http://www.ararteko.net/ RecursosWeb/DOCUMENTOS/1/1 1218 3.pdf

Fondo de las Naciones para la Infancia (UNICEF). (2002). Adolescencia. Una etapa fundamental. Nueva York: Autor. Recuperado de https://www.unicef.org/ecuador/pub adolescence sp.pdf

Garaigordobil, M. (2011). Prevalenciay consecuencias del ciberbullying:Una revisión. International Journal of Psychology \& Psychological Therapy, 11(2), 233-254. Recuperado de http://www. ijpsy.com/volumen11/num2/295/prevalencia-y-consecuencias-del-Ciberbullying-ES.pdf

Hernández, M. y Solano, I. (2007). Ciberbullying. Un problema de acoso escolar. RIED. Revista Iberoamericana de Educación a Distancia, 10(1), 17-36. Recuperado de http://digitum. um.es/xmlui/bitstream/10201/14613/1/ciberbullyng Hernandez Solano 2007.pdf 
Hernández, R., Fernández, C. y Baptista, P. (2003). Metodología de la investigación (2ª ed.). México: McGraw-Hill.

Kowalski, R., Limber, S. y Agatston, P. (2010).CyberBullying: El acoso escolar en la er@ digit@l. España: Desclée De Brouwer.

Luengo, J. A. (2014). Ciberbullying, prevenir y actuar. Hacia una ética de las relaciones en las redes sociales. Guía de recursos didácticos para centros educativos. Madrid: Colegio oficial de psicólogos de Madrid. Recuperado de http://www.copmadrid.org/webcopm/recursos/ CiberbullyingB.pdf

Ministerio de Educación Pública (MEP). (2015). Protocolo de actuación en situaciones de bullying. San José, Costa Rica: MEP, Dirección de Vida Estudiantil y UNICEF. Recuperado de https:// www.unicef.org/costarica/Documento-Protocolo-Bullying.pdf

Molina, J. A. y Vecina, P. (2015). Bullying, ciberbullying y sexting. ¿Cómo actuar ante una situación de acoso? Madrid: Ediciones Pirámide.

Morales, M. E., Chaves, A. L. y Villalobos, M. (2016). Ciberbullying: Conociendo su impacto en el desarrollo socioemocional de la población adolescente y reflexionando acerca de posibles formas de prevenirlo (Informe de investigación). Heredia, Costa Rica: Instituto de Estudios Interdisciplinario de la Niñez y la Adolescencia, Universidad Nacional.

Pérez, R. (2014). Generación móvil. Usos de tecnologías móviles y mediación adulta en niños y niñas de 10 a 13 años del Área Metropolitana de Costa Rica. Recuperado de http://www. crianzatecnologica.org/sites/default/files/recursos apoyo/2014 - generacion movil usos de tecnologias moviles y mediacion adulta en ninos y ninas de 10 a 13 anos del area metropolitana de costa rica.pdf

Sandín, M. P. (2003). Investigación cualitativa en educación. Fundamentos y tradiciones. Madrid: McGraw-Hill.

Taylor, S. y Bodgan, R. (1992). Introducción a los métodos cualitativos. Madrid: Paidós.

Vega, E. (2016). Consecuencias psicológicas del ciberbullying [Mensaje en un blog]. Recuperado de http://desarrolloymovimientoenequilibrio.over-blog.org/2016/03/consecuenciaspsicologicas-del-ciberbullying.html

Vives, M., Sánchez, L., Orte, C. y Macías, L. (2014). El ciberbullying. Conocer para actuar. INNODOCT. Recuperado de http://www.academia.edu/6502658/El Ciberbullying. Conocer para actuar 